\title{
COX-2 Inhibition by Use of Rofecoxib or High Dose Aspirin Enhances ADP-Induced Platelet Aggregation in Fresh Blood
}

\author{
Piet Borgdorff*, M. Louis Handoko, Yeun Ying Wong and Geert Jan Tangelder \\ Institute for Cardiovascular Research, Vrije Universiteit Medical Center, Amsterdam, The Netherlands
}

\begin{abstract}
Aim: Increased cardiovascular risk after use of selective or nonselective cyclooxygenase-2 (COX-2)-inhibitors might partly be caused by enhanced platelet aggregability. However, an effect of COX-2 inhibition on platelets has so far not been observed in humans.

Methods: We tested in healthy volunteers the effect of COX-2-inhibition nearly in-vivo, i.e. immediately after and even during blood sampling.

Results: Measurement within 2 minutes after venipuncture, but not 60 minutes later, showed that $50 \mathrm{mg}$ of rofecoxib $(n=12)$ or $500(n=8)$ or $1000(n=8) \mathrm{mg}$ of aspirin increased ADP-induced platelet aggregation in a whole-blood aggregometer to, respectively, 152, 176 and $204 \%$ of basal level $(\mathrm{p}<0.01)$. No significant differences in aggregability were observed after ingestion of $80 \mathrm{mg}$ of aspirin $(\mathrm{n}=16)$, or placebo $(\mathrm{n}=8)$. Plasma 6-keto-PGF1 $\alpha$ was decreased to $74 \%$ after rofecoxib and to 76 and $70 \%$ after 500 and $1000 \mathrm{mg}$ of aspirin but did not change after low dose aspirin. Continuous photometrical measurement of aggregation in blood flowing from a cannulated vein revealed that high dose aspirin did not elicit aggregation by itself, but increased ADP-induced aggregation in proportion to the decrease in prostacyclin formation $(r=0.68, p=0.004)$. Since in these experiments thromboxane production was virtually absent, the enhanced aggregation after partial COX-2 inhibition was not caused by unopposed thromboxane formation.

Conclusions: We conclude that both selective and nonselective COX-2 inhibition enhances ADP-induced platelet aggregation in humans. This effect can only be detected during or immediately after venipuncture, possibly because of the short half-life of prostacyclin.
\end{abstract}

Key words: platelets, prostacyclin, thromboxane, COX-2-inhibition, aspirin, rofecoxib

\section{INTRODUCTION}

Inhibitors of cyclooxygenase-2 (COX-2) are reported to promote cardiovascular events in patients at atherothrombotic risk. Recent studies have shown that this effect is not specific for selective COX-2 inhibitors but has been demonstrated for nonselective COX-2 inhibitors as well [1-6]. The mechanisms involved remain unclear. In rats we have found that both selective (parecoxib) and nonselective (high dose aspirin) COX-2 inhibitors enhance shear stress-induced platelet aggregation when measured nearly in-vivo, i.e. in an extracorporeal shunt between carotid and femoral artery [7]. However, the hypothesis that COX-2 inhibition increases platelet aggregability also in humans seems to be contradicted by clinical and laboratory studies [8-15].

In these studies the time between blood sampling and aggregation-testing was, as usual in the clinical setting, one hour or more. During that time the reaction of platelets to ADP and collagen increases, reaching a stabile maximum after 30 to 45 minutes [16]. This may seriously hamper and even preclude detection of an increase in platelet aggregability at one hour or more after venipuncture. Moreover, COX-2

*Address correspondence to this author at the Laboratory for Physiology, VUMC, Van der Boechorststraat 7, 1081 BT Amsterdam, The Netherlands; Tel: 31-204448119; Fax: 31-204448255; E-mail: p.borgdorff@vumc.nl derived endogenous platelet antagonists with a short halflife, such as prostacyclin $\left(\mathrm{PGI}_{2}\right)$, which inhibits platelet aggregation with a half-time of $6-10$ minutes in human blood and 11 to 16 minutes in human plasma [17-19], will then have lost their effect. Therefore, we compared in humans the effects of COX-2 inhibition on platelet aggregability at 2 and at 60 minutes after blood sampling, using a conventional whole-blood aggregometer. To approach the in-vivo situation even more, aggregation was in a number of experiments also measured directly in blood flowing from a cannulated vein, with aid of an established photometric device [20]. In addition, we measured circulatory levels of a stabile metabolite of $\mathrm{PGI}_{2}$ before and after $\mathrm{COX}-2$ inhibition

\section{MATERIALS AND METHODS}

\section{Subjects and Protocol}

Healthy non-smoking Caucasian volunteers (aged 20-62 years), who did not use drugs for at least two weeks before enrolment, and who did not exercise, eat fish or drink alcohol within the 12 hours before the experiment, gave informed consent. To reduce the influence of hormonal variation only male subjects were involved, and the effect of circadian variation in platelet aggregability was minimised by starting all experiments at $11.00 \mathrm{~h}$ am, when aggregation is maximal [21]. The effect of selective COX-2 inhibition on 
ADP-induced platelet aggregation was studied by testing aggregation before and $1.5-2$ hours after intake of placebo $(\mathrm{n}=8)$ or $50 \mathrm{mg}$ of rofecoxib (VIOXX, Merck, Sharp and Dohme, now withdrawn from the market, $n=12$ ), which is the recommended dose for relief of acute pain. It reduces COX-2 activity within 1.5 hour after ingestion for at least 10 hours [22], and has no significant effect on COX-1 activity [23]. For nonselective COX-2 inhibition high dose aspirin (Aspro, Bayer) was used in a dose of $500 \mathrm{mg}(\mathrm{n}=8)$ or 1000 $\mathrm{mg}(\mathrm{n}=8)$. Aspirin was also given in low dose: $80 \mathrm{mg}$ (Cardio $80 \mathrm{PCH}, \mathrm{n}=16)$. Low dose aspirin blocks COX-1 mediated platelet thromboxane- $\mathrm{A}_{2}\left(\mathrm{TXA}_{2}\right)$ formation within 20 minutes after ingestion. The blockade lasts for the life-time (approximately 10 days) of the platelets, because they lack the ability to make new protein. The inhibiting effect of low dose aspirin on COX-2 mediated prostacyclin formation in the nucleated endothelial cells is only short-lasting because of protein resynthesis, whereas high dose aspirin reduces endothelial $\mathrm{PGI}_{2}$ synthesis for more than 3 hours [24]. Platelet aggregation was elicited by ADP because ADP plays a central role in initiating and propagating aggregation induced by a variety of agonists, and because ADP-induced aggregation is known to be inhibited by $\mathrm{PGI}_{2}$ [25]. The study protocol was approved by the Medical Ethics Review Committee of our hospital.

\section{Blood Collection}

Blood was collected via an indwelling plastic cannula in an antecubital vein. Because of the possible generation of prostacyclin and other substances that affect platelet activity during cannulation, the first few milliliters were discarded. Part of the blood was added to $3.2 \%$ sodium citrate $(9: 1$ volume ratio) for in-vitro measurement of platelet aggregability, and another part immediately added to a solution of $\mathrm{K}_{3}$-EDTA for measurement of $\mathrm{PGI}_{2}$ levels (see Measurement of prostanoids), and for platelet and other blood cell counts (ABX Diagnostics, Netherlands).

\section{Platelet Aggregation In-Vitro}

To enable immediate measurement of aggregation invitro, blood was collected into a prewarmed syringe and quickly added to a whole-blood aggregometer (Chronolog Corporation, Havertown). Aggregation was elicited by $5 \mu \mathrm{M}$ ADP within exactly 2 minutes after blood collection, and quantified as the change in impedance (ohms) at 6 minutes after addition of the agonist. Only one agonist could be tested in this way, because the aggregometer had only one channel. The unused blood was set apart at room temperature (in an air-free syringe, to prevent loss of $\mathrm{CO}_{2}$ and change of $\mathrm{pH}$ ), and tested 60 minutes later. After the latter test the reaction to $330 \mu \mathrm{M}$ arachidonic acid was measured as well. In a separate set of experiments $(n=8)$ the time-dependency of the platelet reaction to $5 \mu \mathrm{M}$ ADP was more precisely studied by varying the delay between venipuncture and in-vitro aggregation testing (between 2 and 60 minutes) in subjects who had not taken COX-inhibitors.

\section{Platelet Aggregation in Flowing Blood}

In the experiments with high dose aspirin aggregability was measured both in-vitro (see above) and nearly in-vivo by a photometric device that can detect platelet aggregates in flowing blood. For the latter measurement the venous cannula was via tubing connected to a glass capillary on the stage of a microscope. Passing platelet aggregates caused a change in light transmission, which was, after $40 \mathrm{x}$ magnfication, projected on light-sensitive diodes. The rectified and integrated signal was continuously measured [20]. Blood flow through the capillary was stabilized at $2 \mathrm{ml} / \mathrm{min}$ by a small home-made roller pump. Premature platelet activation and clotting were prevented by coating the tubing with albumin and by infusing unfractionated heparin (final concentration $5 \mathrm{IE} / \mathrm{ml}$ blood) into the line before the pump.

Platelet aggregability in flowing blood was tested within 15 seconds after the blood left the body, by two-minute infusions into the tubing of incremental concentrations of ADP $(10,20,30,40$, and $50 \mu \mathrm{M}$ final concentration). This was followed by a two-minute infusion of $20 \mu \mathrm{M}$ epinephrine. During platelet aggregation, induced by $30 \mu \mathrm{M}$ ADP, blood was collected from the end of the tubing in $\mathrm{K}_{3}$-EDTA solution for assessment of plasma $\mathrm{TXA}_{2}$ (see Measurement of prostanoids).

\section{Measurement of Prostanoids}

For enzymeimmunoassays of plasma 6-keto-PGF ${ }_{1 \alpha}$ and $\mathrm{TXB}_{2}$, which are the stabile metabolites of $\mathrm{PGI}_{2}$ and $\mathrm{TXA}_{2}$, respectively, EDTA-blood was centrifuged at $3500 \mathrm{~g}$ for 20 minutes and the platelet poor plasma stored in $-80{ }^{\circ} \mathrm{C}$ until analysis by EIA Biotrak systems (Amersham Biosciences, detection limits: 3.0 and $3.6 \mathrm{pg} / \mathrm{ml}$, respectively). Before analysis the prostaglandins were separated from fatty acids using Amprep ${ }^{\mathrm{TM}}$ minicolumns and solvent extraction, according to the manufacturer's instructions. Samples selected for measurement of 6-keto-PGF ${ }_{1 \alpha}$ were divided before analysis and one part was spiked with 6-keto-PGF $1 \alpha$ for estimation of recovery. All assays were performed in duplicate.

\section{Statistics}

Values are given as mean \pm standard error of the mean (SEM). The effects of selective or nonselective COX-2 inhibition on the amount of platelet aggregation at different time points (in the whole-blood aggregometer), or for several doses of ADP (in flowing blood), were analysed by two-way ANOVA for repeated measurements, followed by a Bonferroni test. Plasma levels of $\mathrm{PGI}_{2}$ and $\mathrm{TXA}_{2}$ metabolites were compared with one-way ANOVA or the paired t-test. Statistical significance was set at $\mathrm{P}<0.05$.

\section{RESULTS}

\section{Platelet Aggregation In-Vitro}

Measurement of aggregation at two minutes after blood collection showed that ingestion of a single dose of $50 \mathrm{mg}$ rofecoxib, in contrast to placebo, caused an increase in ADPinduced platelet aggregation (to $152 \%$ of basal value, Fig. 1 and Table 1). This increase could not been observed at 60 minutes after venipuncture. The selectivity of rofecoxib as COX-2 inhibitor was demonstrated by an unchanged reaction to arachidonic acid (Table 1).

Comparable results were found with nonselective COXinhibition by high dose aspirin. Whereas low dose aspirin $(80 \mathrm{mg})$ had no effect, higher doses of aspirin (500 and 1000 

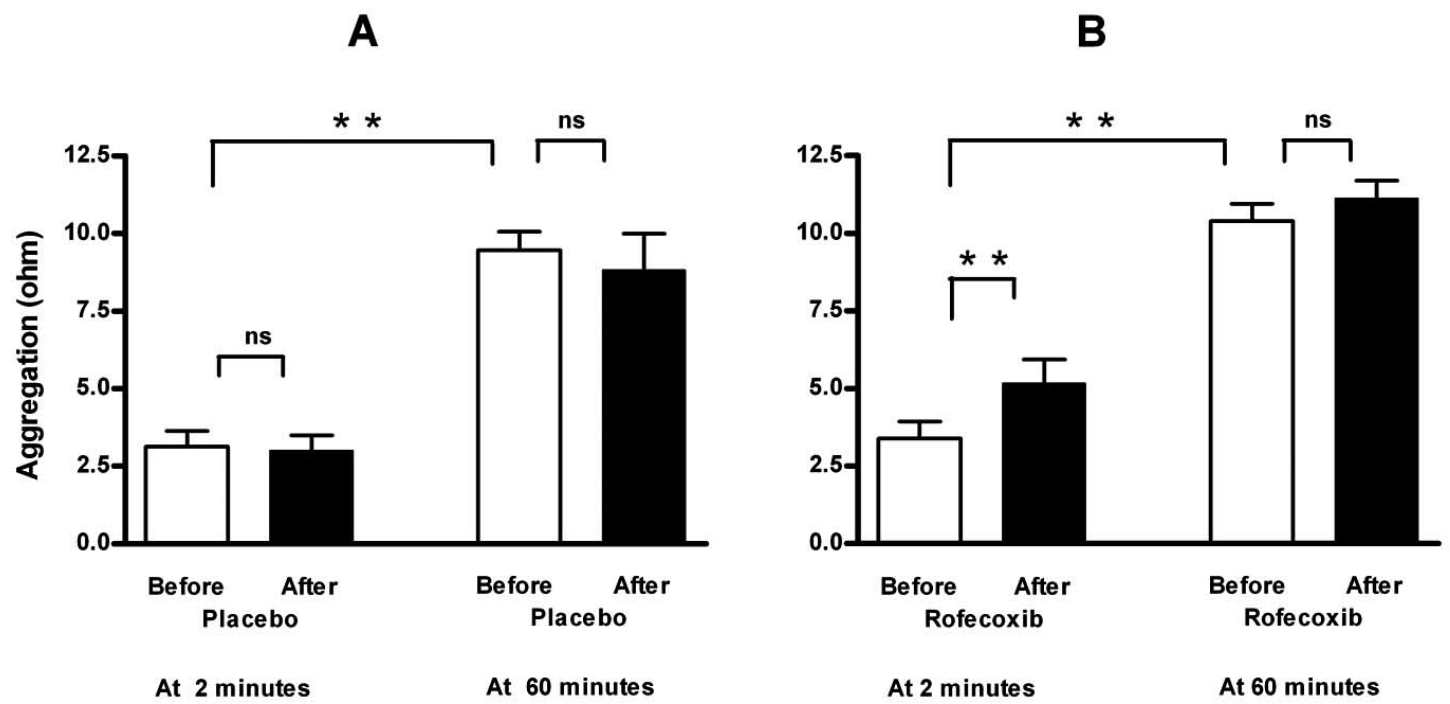

Fig. (1). Effect of placebo $(\mathbf{A}, \mathrm{n}=8)$ and selective COX-2 inhibition by a single oral dose of $50 \mathrm{mg}$ rofecoxib (B, $\mathrm{n}=12)$ on ADP-induced platelet aggregation in a conventional whole-blood aggregometer. Enhancement by selective COX-2 inhibition is demonstrable at two minutes after blood collection, but not when the blood is set apart for 60 minutes. Means \pm SEM of maximal value in ohms after application of $5 \mu \mathrm{M}$ ADP. $* *=\mathrm{p}<0.01, \mathrm{~ns}=$ not significant.

Table 1. Effect of a Single Dose of Rofecoxib $(50 \mathrm{mg})$ or Aspirin on In-Vitro Platelet Aggregation in a whole Blood Aggregometer at 2 and 60 Minutes after Blood Sampling

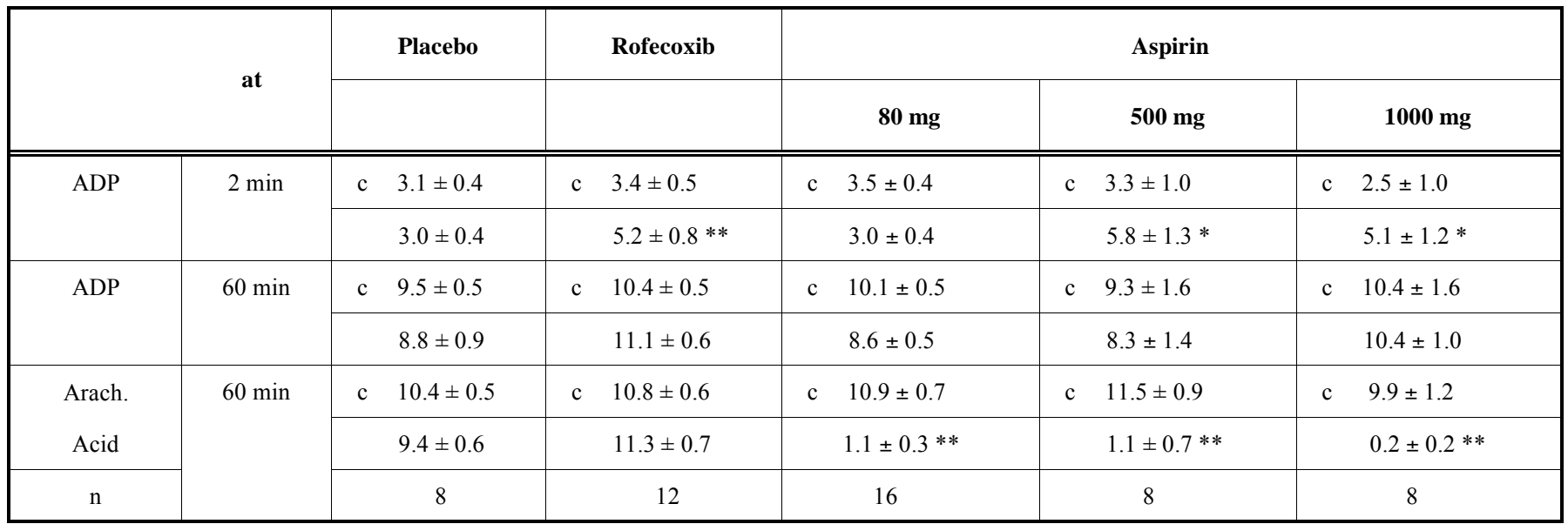

Maximal reactions to ADP $(5 \mu \mathrm{M})$ and arachidonic acid $(333 \mu \mathrm{M})$ in ohms (means \pm SEM). $\mathrm{c}=$ control condition before ingestion of the study drug. $*=p<0.05$ and $* *=p<0.01$, compared to control.

$\mathrm{mg}$ ) elicited a similar increase in aggregation as rofecoxib did (Fig. 2 and Table 1). This was, again, demonstrable only when aggregation was measured immediately after blood sampling, but not when the blood was set apart and aggregation elicited 60 minutes later. Reactions to arachidonic acid (measured only after more than 60 minutes) were suppressed by all doses of aspirin (Table $\mathbf{1}$ ).

Time-dependency of the in-vitro platelet reaction to ADP in subjects who had not taken COX-inhibitors is depicted in Fig. (3). Platelet aggregability (y) increased with the delay between venipuncture and aggregation testing $(\mathrm{x})$ according to $y=8.75-6.73 \cdot e^{-0.079} \cdot x$, and reached a plateau at about 45 minutes. The time to reach half the maximal value was 8.8 minutes. The level at 60 minutes was similar for arachidonicand for ADP-induced aggregation (Table 1), suggesting a maximal response, and illustrating the necessity to measure a possible increase in aggregability not at 60 minutes but quickly after venipuncture.

\section{Platelet Aggregation in Flowing Blood}

The rather unexpected findings with high dose aspirin were corroborated by testing platelet aggregability directly in blood flowing from a cannulated vein. In unstimulated blood no spontaneous platelet aggregation was detected, neither in control nor after aspirin ingestion. This indicates that high dose aspirin by itself did not elicit aggregation. In accordance, platelet counts were not significantly diminished (261 $\pm 14 \times 10^{9} / \mathrm{L}$ versus $275 \pm 12 \times 10^{9} / \mathrm{L}$ in control), and other cell counts remained within normal ranges (not shown). Addition of ADP elicited a dose-dependent increase in aggregation (for an example see Fig. 4A). These responses were enhanced to $160 \pm 20 \%$ of control $((p<0.0001$, Fig. 4B $)$ after 
A

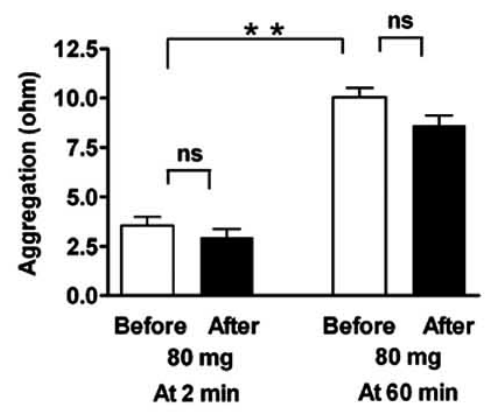

B

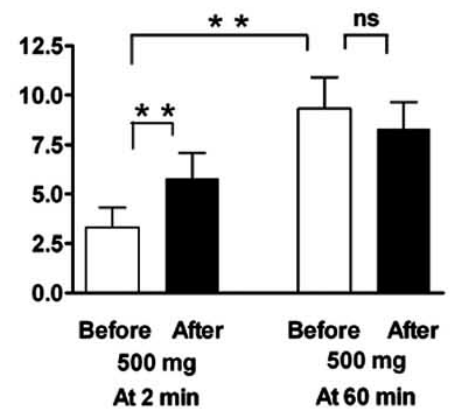

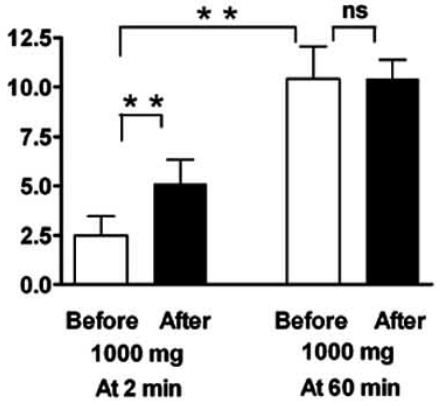

Fig. (2). Effect of a single oral dose of $80 \mathrm{mg}(\mathrm{A}, \mathrm{n}=16), 500 \mathrm{mg}(\mathrm{B}, \mathrm{n}=8)$, and $1000 \mathrm{mg}(\mathrm{C}, \mathrm{n}=8)$ of aspirin on ADP-induced platelet aggregation in a conventional whole-blood aggregometer. Enhancement by the higher doses of aspirin (nonselective COX-2 inhibition) is demonstrable at two minutes after blood collection, but not when the blood is set apart for 60 minutes. Means \pm SEM of maximal value in ohms after application of $5 \mu \mathrm{M}$ ADP. $* *=\mathrm{p}<0.01$, ns $=$ not significant.

ingestion of high dose aspirin, without a significant difference between experiments with 500 or with $1000 \mathrm{mg}$ of aspirin. This enhancement was unlikely caused by unopposed $\mathrm{TXA}_{2}$ activity, because $\mathrm{TXA}_{2}$-generation during ADPinduced platelet aggregation in flowing blood was markedly reduced after aspirin (from $552 \pm 96$ to $30 \pm 7 \mathrm{pg} / \mathrm{ml}$, p < $0.0001)$.

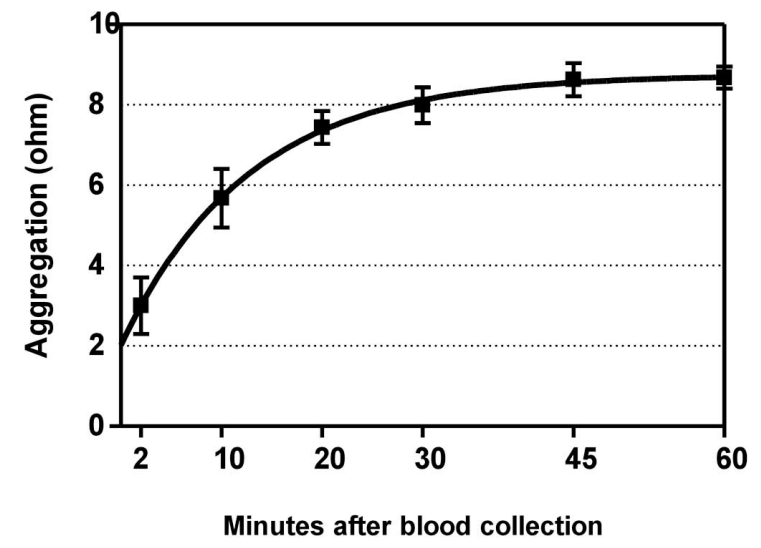

Fig. (3). Time-dependent increase of ADP-induced platelet aggregation after venipuncture. Means \pm SEM of maximal value in ohms after application of $5 \mu \mathrm{M}$ ADP to whole blood. Half-time of the fitted curve was 8.8 minutes. Blood was collected from subjects $(n=8)$ who had not ingested a COX-2 inhibitor, and was kept in closed tubes at room temperature.

Also reactions of the platelets to $20 \mu \mathrm{M}$ of epinephrine, injected after the series of ADP additions, tended to be stronger after high dose aspirin $(146 \pm 22 \%$ of control, $\mathrm{p}=0.09$ ).

\section{Prostacyclin}

Basal levels of plasma 6-keto-PGF $1 \alpha$, the stabile metabolite of prostacyclin, were reduced after a single dose of rofecoxib (to $74 \%$ ) and after the higher doses of aspirin (to $76 \%$ after $500 \mathrm{mg}$ and to $70 \%$ after $1000 \mathrm{mg}$ ), but not after low dose aspirin (to $98 \%$ ) (Fig. 5). When aggregation was tested in flowing blood, a positive correlation (Pearson $\mathrm{r}=0.68, \mathrm{p}=0.004$ ) was found between the individual amount of 6-keto-PGF $1 \alpha$ reduction and the aspirin-induced increase of platelet aggregation (averaged for the five doses of ADP).

\section{DISCUSSION}

This study shows that both selective and nonselective COX-2 inhibition by, respectively, rofecoxib or high dose aspirin enhances ADP-induced platelet aggregation in healthy humans. This enhancement was demonstrable only with near-in-vivo measurement of platelet aggregation in blood flowing from a cannulated vein, or in-vitro with a whole blood aggregometer, if aggregation was tested within the first minutes after blood sampling, but not if the blood was set apart and the measurements postponed for one hour. The present study extends previous findings of increased platelet aggregability after COX-2 inhibition in rats [7], and is in line with studies showing increased platelet adhesion in hamster arterioles [26] and rabbit injured carotid arteries [27], after COX-2 inhibition.

\section{COX-2 Inhibition and Increased Thrombotic Risk}

During measurement of platelet aggregation in blood flowing from a cannulated vein no aggregates were detected as long as platelets were not stimulated by an exogenous agonist, neither in control nor after partial COX-2 inhibition by aspirin. Therefore, COX-2 inhibition did not by itself elicit platelet aggregation. This suggests that inhibition of COX-2 in healthy man is of limited risk. In cardiovascular patients, however, COX-2 inhibition might amplify aggregation elicited by e.g. rupture of an atherosclerotic plaque or further narrowing of a vascular stenosis.

The results with an adult dose of aspirin (500-1000 mg) contrasts to the well known beneficial effect of low dose aspirin in preventing restenosis. It might, however, explain why in the Cottbus study significantly more reinfarctions were seen with $1000 \mathrm{mg}$ of aspirin per day than with 30 or $60 \mathrm{mg} /$ day [28]. Also more recent studies showed that the risk of stroke, myocardial infarction, and death was significantly greater for patients taking higher doses of aspirin (650-1300 mg) compared to those taking lower doses (81$325 \mathrm{mg}$ ) [29-32]. The results with high dose aspirin show at the same time that it is not the selectivity of COX-2 inhibitors that makes them prothrombotic. This could explain why cardiovascular risk is also increased by use of nonselective COX inhibitors like ibuprofen and diclofenac (hazard ratios of, respectively, 1.51 and 1.63 [2-6]). 
A
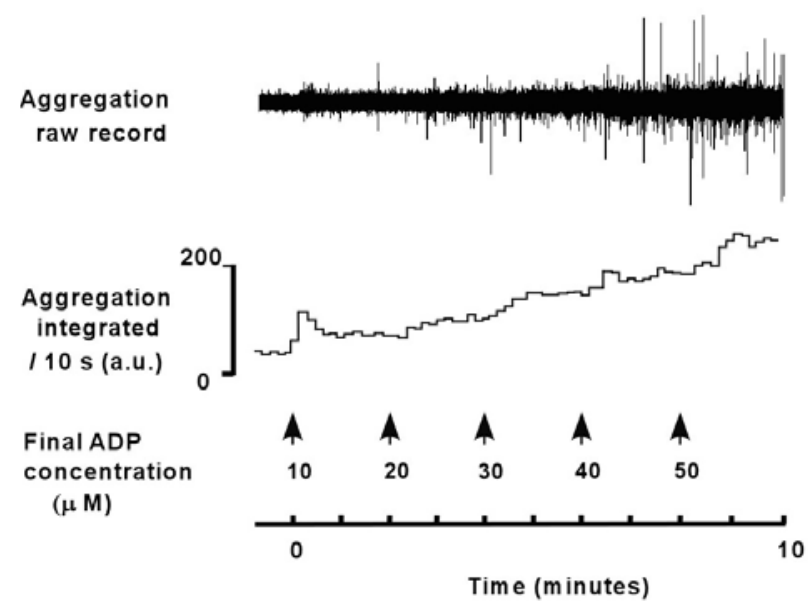

B

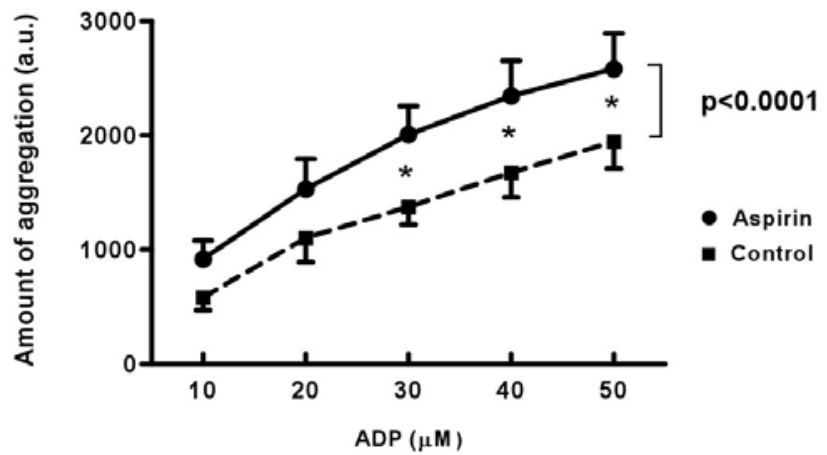

Fig. (4). A. Platelet aggregation in flowing blood is induced by infusion of increasing concentrations of ADP into tubing connected to a cannulated vein. The aggregates were detected photometrically when they passed a glass capillary connected to the tubing. Raw signals are rectified and integrated over periods of ten seconds. A.u.: arbitrary units. B. Platelet aggregation measured directly in flowing blood is enhanced by ingestion of a high dose of aspirin (pooled data for 500 and $1000 \mathrm{mg}$ ). Means \pm SEM represent the total amount of aggregation during two minutes of ADP-infusion, before and after high dose aspirin. ${ }^{*}=\mathrm{p}<0.05$. Overall difference between aspirin and control: $\mathrm{p}<0.0001$.

A

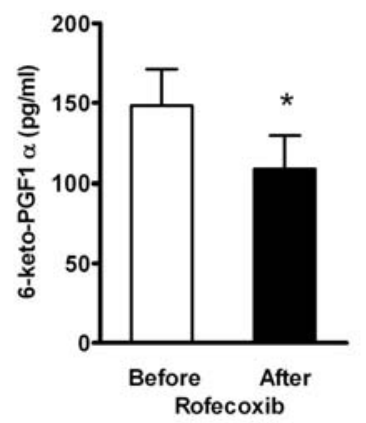

B

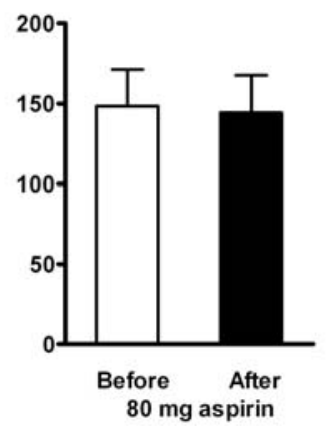

C

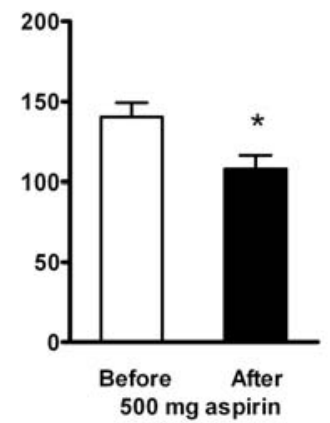

D

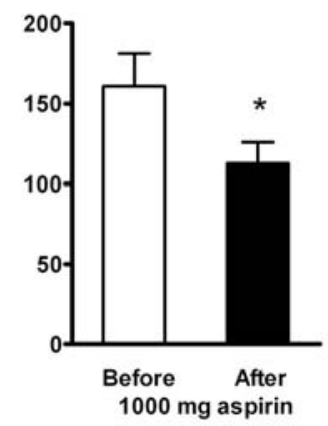

Fig. (5). Effect of a single dose of $50 \mathrm{mg}$ of rofecoxib $(\mathbf{A}, \mathrm{n}=12)$ and of aspirin in doses of $80 \mathrm{mg}(\mathbf{B}, \mathrm{n}=16), 500 \mathrm{mg}(\mathbf{C}, \mathrm{n}=8)$, and $1000 \mathrm{mg}$ $(\mathbf{D}, \mathrm{n}=8)$ on plasma levels of 6-keto-PGF1 $\alpha$. Means \pm SEM. $*=\mathrm{p}<0.05$.

\section{Time-Dependency of Platelet Aggregation}

Our near in-vivo measurements explain why the stimulating effect of COX-2 inhibition on platelet aggregation has not been detected in clinical settings where measurements are usually delayed by transport of the blood samples to a local laboratory [8-15]. Hence, our findings show that important information about the thrombotic risk of a patient may be missed when aggregation is not measured immediately after venipuncture.

A time-dependent increase of platelet aggregability after venipuncture (see our Fig. 3) has been found earlier by other investigators using whole blood analysers [16] or flow cytometry [33], indicating that the method used is irrelevant. Inoue et al. [34], using the screen filtration method, found that an enhancing effect of cigarette smoking on platelet aggregation was demonstrable only at 5 minutes, but not at 60 minutes. These findings are compatible with our results, particularly because smoking is, just as COX-2 inhibition, known to inhibit $\mathrm{PGI}_{2}$ formation [35].
The mechanism for the time-dependent increase in platelet aggregability after venipuncture awaits to be clarified. It has been postulated that the increase is caused by a temperature-dependent change in the intra-platelet calcium level [16], or by degradation of labile platelet inhibitors like $\mathrm{PGI}_{2}$, EDRF/NO and ecto-ADPases.

\section{Thromboxane $A_{2}$ is not Essential for the Enhancement of ADP-Induced Platelet Aggregation by COX-2 Inhibition}

A common hypothesis states that selective COX-2 inhibitors might be prothrombotic by inhibiting prostacyclin formation while leaving COX-1 induced thromboxane formation unopposed, in this way disturbing the balance between suppression and promotion of aggregation [26]. In our experiments with high dose aspirin, however, thromboxane formation was nearly abolished. Hence, the increase of ADPinduced aggregation in these experiments was not an effect of unopposed $\mathrm{TXA}_{2}$ formation. This might be explained by the fact that thromboxane plays a minor role only in ADP- 
Table 2. Literature Data on Mean Basal Levels of Plasma 6-keto-PGF1a

\begin{tabular}{|c|c|c|c|}
\hline RIA & healthy adults & $291,245,182,161,126,115,110,88,85,26$ & {$[\mathrm{i}-\mathrm{x}]$} \\
\hline $\begin{array}{l}\text { RIA after separation } \\
\text { on charcoal or HPLC }\end{array}$ & healthy adults & $<7.5,4.7,1.7,1$ & [xx-xxiii] \\
\hline ELISA & patients before surgery & 200,57 & {$[\mathrm{xxx}, \mathrm{xxxi}]$} \\
\hline
\end{tabular}

RIA: radioimmunoassay. HPLC: High Performance Liquid Chromatography. ELISA: Enzyme-Linked Immuno Sorbent Assay. For references see APPENDIX

induced aggregation [36, 37]. Although in the clinical situation also $\mathrm{TXA}_{2}$-dependent agonists will be involved, various studies showed that the risk of myocardial infarction was not reduced when the use of a selective COX-2 inhibitor was combined with low dose aspirin $[5,38]$.

\section{Possible Role of Prostacyclin}

Selective or nonselective COX-2 inhibition by a single dose of respectively rofecoxib or high dose aspirin reduced the plasma $\mathrm{PGI}_{2}$ levels by 24 to $30 \%$. Although this reduction may seem moderate, ADP-induced platelet aggregation was enhanced by 52 to $60 \%$. It might be speculated that this enhancement will be even stronger with daily use of COX-2 inhibitors. Measurement of aggregation in blood flowing from a cannulated vein furthermore revealed a significant correlation between the increase in aggregation and the degree of $\mathrm{PGI}_{2}$ reduction. These results give for the first time direct evidence for the hypothesis of Moncada and Vane [39], i.e. that the basal level of circulating endogenous $\mathrm{PGI}_{2}$ is sufficiently high to partially depress platelet aggregation in human blood. This hypothesis was rejected in earlier studies, with the argument that the $\mathrm{PGI}_{2}$-levels in circulating blood are too low to influence platelet aggregability [40]. Table 2 shows, however, a number of studies in which levels of $\mathrm{PGI}_{2}$ were found comparable to those found in the present study.

The inhibiting influence of PGI2 on platelets has been thought to occur via stimulation of platelet adenylate cyclase and elevation of platelet cAMP, which reduces intracellular levels of free calcium [41-43].

Our finding that COX-2 inhibition did not by itself elicit platelet aggregation complies with the absence of spontaneous thrombosis in mice lacking receptors for $\mathrm{PGI}_{2}$ [44], and the observation of Arehart et al. [45] in patients with a naturally occurring mutation in the prostacyclin receptor. These authors conclude that a deficiency in prostacyclin signaling is not likely an initiating factor in cardiovascular disease but accelerates the course of disease in those patients with the greatest risk factors.

Reduction of $\mathrm{PGI}_{2}$ synthesis is not exclusively caused by use of selective or nonselective COX-2 inhibitors, or by smoking, but may also occur in several diseases, including diabetes [46], or might result from use of medicines, e.g. inhibitors of vascular endothelial growth factor (VEGF) in cancer patients [47]. In addition, plasmatic half-life of $\mathrm{PGI}_{2}$ is significantly shortened during severe infections, and in acute myocardial infarction $[17,48]$, and in general, by lowered levels of HDL-c and apoA1, the latter being described as a potential $\mathrm{PGI}_{2}$-stabilising factor [17]. Our findings suggest that in all such conditions important information about the thrombophilic status of a patient will be overlooked if platelet aggregability is not tested immediately after blood collection ("near patient measurement").

\section{STUDY LIMITATIONS}

The results of this study are based on experiments with a limited number of healthy non-smoking male subjects under controlled conditions. They did not use drugs for at least two weeks before enrolment, and did not exercise, eat fish or drink alcohol within the 12 hours before the experiment, and the effect of circadian variation in platelet aggregability was minimised by starting all experiments at $11.00 \mathrm{~h}$ am. It remains to be demonstrated that the enhancing effect of COX2 inhibition on platelet aggregability is also present in women, and in less controlled conditions.

To demonstrate that the effect of COX-2 inhibition on platelet aggregability in-vitro can only be observed when platelet aggregability is tested immediately after blood collection, only one agonist (ADP) was used, because our aggregometer had only one channel. The experiments might be repeated with other platelet agonists.

\section{CONCLUSION}

Reduction of endogenous $\mathrm{PGI}_{2}$ by intake of selective or nonselective COX-2 inhibitors enhances ADP-induced platelet aggregation in humans. This can be demonstrated when aggregation is measured during the first minutes after blood withdrawal, but not one hour later. The results imply, first, that the level of endogenous $\mathrm{PGI}_{2}$ is sufficiently high to continuously reduce platelet aggregation under basal conditions; second, that the enhancement of aggregability by $\mathrm{COX}-2$ inhibition does not necessarily depend on increased $\mathrm{TXA}_{2}$ activity; and, third, that important information about the thrombotic risk of a patient may be missed when aggregation is not measured immediately after venipuncture. Our results underline the concept that use of COX-2 inhibitors increases the risk for cardiovascular events by creating a prothrombotic environment. 


\section{CONFLICT OF INTEREST STATEMENT}

We declare that we have no conflict of interest.

\section{ACKNOWLEDGEMENTS}

We thank M.H. van Wijhe for the measurement of 6-keto-Prostaglandin $\mathrm{F}_{1 \alpha}$ and Thromboxane B2, and Prof. Dr. V.W. M. van Hinsbergh for critical reading of the manuscript.

\section{APPENDIX}

\section{References for Table 2}

[i] Ylikorkala O, Puolakka J, Viinikka L. Oestrogen containing oral contraceptives decrease prostacyclin production. Lancet 1981; 3: 42.

[ii] Komori T, Fujii S, Nogi O, Ohashi M, Sasakawa O, Yamamoto K. Prostacyclin Production Reduced in Diabetics with Vascular Complications. Jap J Med 1985; 24: 231

[iii] Ylikorkala D, Viinikka L. Measurement of 6-keto-prostaglandin F1 alpha in human plasma with radioimmunoassay: effect of prostacyclin infusion. Prostaglandins Med 1981; 6: 427-36.

[iv] Chavarria ME, Lara-González L, González-Gleason A, GarcíaPaleta Y, Vital-Reyes VS, Reyes A. Prostacyclin/thromboxane early changes in pregnancies that are complicated by preeclampsia. Am J Obstet Gynecol 2003; 188: 986-92.

[v] Sekine M. A radioimmunoassay of 6-keto PG F1 alpha using [125I]-6-keto PG F1 alpha-tyramide. Nippon Naibunpi Gakkai Zasshi 1985; 61: 1-13.

[vi] Mitchell MD. A sensitive radioimmunoassay for 6-ketoprostaglandin F1alpha: preliminary observations on circulating concentrations. Prostaglandins Med 1978; 1: 13-21.

[vii] van der Poll T, van Deventer SJ, Buller HR, Sturk A, ten Cate JW. Comparison of the early dynamics of systemic prostacyclin release after administration of tumor necrosis factor and endotoxin to healthy humans. J Infect Dis 1991; 164: 599-601.

[viii] Ylikorkala O, Osterman T, Lindén IB, Viinikka L. The effect of age on circulating 6-keto-prostaglandin F1 alpha in humans. Prostaglandins Leukot Med 1982; 9: 569-75.

[ix] Kääpä P, Viinikka L, Ylikorkala O. Plasma prostacyclin from birth to adolescence. Arch Dis Child 1982; 57: 459-461.

[x] Chai SB, Hui YM, Li XM, Tang CS. Plasma level of mitochondrial coupling factor 6 increases in patients with coronary heart disease. Circ J 2007; 71: 693-7.

[xi] Uotila P, Suyes M, Heikkilä H, Jalonen J. Prostanoids and hemodynamics in man during cardiopulmonary bypass. Prostaglandins 1984; 28: 497-508.

[xii] Faymonville ME, Deby-Dupont G, Larbuisson R, et al. Prostaglandin $E_{2}$, prostacyclin, and thromboxane changes during nonpulsatile cardiopulmonary bypass in humans. J Thorac Cardiovasc Surg 1986; 91: 858-66.

[xiii] Vernon-van Heerden P, Barden A, Michlopoulos N, Bulsara MK, Roberts BL. Dose-response to inhaled aerosolized prostacyclin for hypoxemia due to ARDS. Chest 2000; 117: 819-27.

[xiv] Greeley WJ, Bushman GA, Kong DL, Oldham HN, Peterson MB. Effects of cardiopulmonary bypass on eicosanoid metabolism during pediatric cardiovascular surgery. J Thorac Cardiovasc Surg 1988; 95: 842-9.

[xv] Ylikorkala O, Mäkilä UM, Viinikka L. Effect of vacuum curettage on the concentrations of plasma 6-keto-prostaglandin F1 alpha and serum thromboxane B2. Br J Obstet Gynaecol 1983; 90: 251-4.

[xvi] Nakamura H, Kim DK, Philbin DM, et al. Heparin-enhanced Plasma Phospholipase A2 Activity and Prostacyclin in Patients Synthesis Cardiac Undergoing Surgery. J Clin Invest 1995; 95: 1062-1070.

[xvii] Brinkmann A, Wolf CF, Berger D, et al. Perioperative endotoxemia and bacterial translocation during major abdominal surgery: evidence for the protective effect of endogenous prostacyclin? Crit-Care-Med 1996; 24: 1293-301.

[xviii] Watkins WD, Peterson MB, Kong DL, et al. Thromboxane and prostacyclin changes during cardiopulmonary bypass with and without pulsatile flow. J Thorac Cardiovasc Surg 1982; 84: 250-6

[xix] Matsumoto M, Ohki K, Nagai I, Oshibuchi T. Lung traction causes an increase in plasma prostacyclin concentration and decrease in mean arterial blood pressure. Anesth Analg 1992; 75: 773-6. [xx] Patrono C, Pugliese F, Ciabattoni G, et al. Evidence for a direct stimulatory effect of prostacyclin on renin release in man. $\mathrm{J}$ Clin Invest 1982; 69: 231-239.

[xxi] Siess W, Dray F. Very low levels of 6-keto-prostaglandin F1 alpha in human plasma. J Lab Clin.Med.1982; 99: 388-98.

[xxii] Mourits-Andersen T, Jensen IW, Jensen PN, Ditzel J, Dyerberg J. Plasma 6-keto- $\mathrm{PGF}_{1}$, thromboxane $\mathrm{B}_{2}$ and $\mathrm{PGE}_{2}$ in Type 1 (insulindependent) diabetic patients during exercise. Diabetologia 1987; 30: 460-463.

[xxiii] Stampfer MJ, Jacubowski JA, Faigel D, Vaillantcourt R, Deykin D. Vitamin E supplementation effect on human platelet function, arachidonic acid metabolism, and plasma prostacyclin levels1. Am J Clin Nutr 1988; 47: 700-6.

[xxiv] Polagruto JA, Schramm DD, Wang-Polagruto JF, Lee L, Keen Cl Effects of Flavonoid-Rich Beverages on Prostacyclin Synthesis in Humans and Human Aortic Endothelial Cells: Association with Ex Vivo Platelet Function. J Med Food 2003; 6(4): 301-308.

[xxv] Pignone A, Del Rosso A, Bridget Brosnihan K, et al. Reduced circulating levels of angiotensin-(1-7) in systemic sclerosis: a new pathway in the dysregulation of endothelial-dependent vascular tone control. Ann Rheum Dis 2007; 66:1305-1310.

[xxvi] Schramm DD, Wang JF, Holt RR, et al. Chocolate procyanidins decrease the leukotriene-prostacyclin ratio in humans and human aortic endothelial cells. Am J Clin Nutr 2001; 73: 36-40.

[xxvii] Chen G, Wilson R, Cumming G, Walker JJ, Smith WE, McKillop JH. Prostacyclin, thomboxane and antioxidant lvels in pregnancyinduced hypertension. Eur J Obstetrics Reproductive Biology 1993; 50: 243-250.

[xxviii] Zoladz1 JA, Majerczak J, Duda K, Chlopicki S. Exercise-induced prostacyclin release positively correlates with VO2max in young healthy men. Physiol Res 2009; 58: 229-38

[xxix] Feng D, Murillo J, Jadhav $\mathrm{P}$, et al. Upright posture and maximal exercise and prostacyclin production in healthy male subjects in crease platelet aggregability. Br J Sports Med 1999; 33: 401-404.

[xxx] Bucher M, Kees FK, Messmann B, et al. Prostaglandin I2 release following mesenteric traction during abdominal surgery is mediated by cyclooxygenase-1. Eur J Pharmacol 2006; 536: 296-300.

[xxxi] Knothe CH, Boldt J, Zickmann B, et al. Influence of different flow modi during extracorporeal circulation on endothelial-derived vasoactive substances. Perfusion 1995; 10: 229-236.

\section{REFERENCES}

[1] Haara M, Heliovaara M, Arokoski JP, et al. Regular use of traditional analgesics predicts major coronary events: a cohort study. Ther Clin Risk Manage 2009; 5: 9-15.

[2] Hudson M, Richard H, Pilote L. Differences in outcomes of patients with congestive heart failure prescribed celecoxib, rofecoxib, or non-steroidal anti-inflammatory drugs: population based study. Br Med J 2005; 330: 1370 .

[3] McGettigan P, Henry D. Cardiovascular Risk and Inhibition of Cyclooxygenase: A Systematic Review of the Observational Studies of Selective and Nonselective Inhibitors of Cyclooxygenase 2. JAMA 2006; 296: 1633-44.

[4] Kearney PM, Baigent C, Godwin J, Halls H, Emberson JR, Patrono C. Do selective cyclo-oxygenase-2 inhibitors and traditional non-steroidal anti-inflammatory drugs increase the risk of atherothrombosis? Meta-analysis of randomised trials. Br Med J 2006; 332: 1302-8

[5] Hippisley-Cox J, Coupland C. Risk of myocardial infarction in patients taking cyclo-oxygenase- 2 inhibitors or conventional nonsteroidal anti-inflammatory drugs: population based nested casecontrol analysis. Br Med J 2005; 330: 1366.

[6] Salinas G, Rangasetty UC, Uretsky BF, Birnbaum Y. The cycloxygenase 2 (COX-2) story: it's time to explain, not inflame. J Cardiovasc Pharmacol Ther 2007; 12:98-111.

[7] Borgdorff P, Tangelder GJ, Paulus WJ. Cyclooxygenase-2 inhibitors enhance shear stress-induced platelet aggregation. J Am Coll Cardiol 2006; 48: 817-23.

[8] Knijff-Dutmer EA, Kalsbeek-Batenburg EM, Koerts J, van de Laar MA. Platelet function is inhibited by non-selective non-steroidal anti-inflammatory drugs but not by cyclo-oxygenase-2-selective inhibitors in patients with rheumatoid arthritis. Rheumatology (Oxford) $2002 ; 41: 458-61$.

[9] Greenberg HE, Gottesdiener K, Huntington M, et al. A new cyclooxygenase-2 inhibitor, rofecoxib (VIOXX), did not alter the an- 
tiplatelet effects of low-dose aspirin in healthy volunteers. J Clin Pharmacol 2000; 40: 1509-15.

[10] Rinder HM, Tracey JB, Souhrada M, Wang C, Gagnier RP, Wood CC. Effects of meloxicam on platelet function in healthy adults: a randomized, double-blind, placebo-controlled trial. J Clin Pharmacol 2002; 42: 881-6.

[11] Van Hecken A, Schwartz JI, Depre M, et al. Comparative inhibitory activity of rofecoxib, meloxicam, diclofenac, ibuprofen, and naproxen on COX-2 versus COX-1 in healthy volunteers. J Clin Pharmacol 2000; 40: 1109-20.

[12] Leese PT, Recker DP, Kent JD. The COX-2 selective inhibitor, valdecoxib, does not impair platelet function in the elderly: results of a randomized controlled trial. J Clin Pharmacol 2003; 43: 50413.

[13] Leese PT, Hubbard RC, Karim A, Isakson PC, Yu SS, Geis GS. Effects of celecoxib, a novel cyclooxygenase- 2 inhibitor, on platelet function in healthy adults: a randomized, controlled trial. J Clin Pharmacol 2000; 40: 124-32.

[14] Jermany J, Branson J, Schmouder R, Guillaume M, Rordorf C. Lumiracoxib does not affect the ex vivo antiplatelet aggregation activity of low-dose aspirin in healthy subjects. J Clin Pharmacol 2005; 45: 1172-78.

[15] Graff J, Skarke C, Klinkhardt U, et al. Effects of selective COX-2 inhibition on prostanoids and platelet physiology in young healthy volunteers. J Thromb Haemost 2007; 5: 2376-85.

[16] Qi R, Yatomi Y, Ozaki Y. Effects of incubation time, temperature, and anticoagulants on platelet aggregation in whole blood. Thromb Res 2001; 101:139-44.

[17] Pirich C, Efthimiou Y, O'Grady J, Sinzinger H. Hyperalphalipoproteinemia and prostaglandin I2 stability. Thromb Res 1997; 88: 419 .

[18] Lucas FV, Skrinska VA, Chisolm GM, Hesse BL. Stability of prostacyclin in human and rabbit whole blood and plasma. Thromb Res 1986; 43: 379-87.

[19] Polterauer P, Sinzinger H, Peskar BA. Biological half-life of prostacyclin and 6-oxo-PGF1 alpha levels in plasma of patients with colonic cancer. Prostaglandins Leukot Med 1986; 22: 249-58.

[20] Borgdorff P, Fekkes D, Tangelder GJ. Hypotension caused by extracorporeal circulation: serotonin from pump-activated platelets triggers nitric oxide release. Circulation 2002; 106: 2588-93.

[21] Jovicic A, Mandic S. Circadian variations of platelet aggregability and fibrinolytic activity in healthy subjects. Thromb Res 1991; 62: 65-74.

[22] Depre M, Ehrich E, Van Hecken A, et al. Pharmacokinetics, COX2 specificity, and tolerability of supratherapeutic doses of rofecoxib in humans. Eur J Clin Pharmacol 2000; 56: 167-74.

[23] Ahuja N, Singh A, Singh B. Rofecoxib: an update on physicochemical, pharmaceutical, pharmacodynamic and pharmacokinetic aspects. J Pharm Pharmacol 2003; 55: 859-94.

[24] Vesterqvist O. Rapid recovery of in vivo prostacyclin formation after inhibition by aspirin. Evidence from measurements of the major urinary metabolite of prostacyclin by GC-MS. Eur J Clin Pharmacol 1986; 30: 69-73.

[25] Saniabadi AR, Belch JJ, Lowe GD, Barbenel JC, Forbes CD. Comparison of inhibitory actions of prostacyclin and a new prostacyclin analogue on the aggregation of human platelet in whole blood. Haemostasis 1987; 17: 147-53.

[26] Buerkle MA, Lehrer S, Sohn HY, Conzen P, Pohl U, Krotz F. Selective inhibition of cyclooxygenase-2 enhances platelet adhesion in hamster arterioles in vivo. Circulation 2004; 110: 2053-2059.

[27] Buchanan MR, Hirsh J. Effect of aspirin and salicylate on plateletvessel wall interactions in rabbits. Arteriosclerosis 1984; 4: 403-6.

[28] Forster W, Hoffmann W. Superior prevention of reinfarction by 30 $\mathrm{mg} / \mathrm{d}$ aspirin compared with $1000 \mathrm{mg} / \mathrm{d}$ : results of a two years follow-up study in Cottbus. Biomed Biochim Acta 1988; 47: S248S51.
[29] Taylor DW, Barnett HJ, Haynes RB, et al. Low-dose and high-dose acetylsalicylic acid for patients undergoing carotid endarterectomy: a randomised controlled trial. ASA and Carotid Endarterectomy (ACE) Trial Collaborators. Lancet 1999; 353: 2179-84.

[30] Peters RJ, Mehta SR, Fox KA, et al. Effects of aspirin dose when used alone or in combination with clopidogrel in patients with acute coronary syndromes: observations from the Clopidogrel in Unstable angina to prevent Recurrent Events (CURE) study. Circulation 2003; 108: 1682-7.

[31] Kong DF, Hasselblad V, Kandzari DE, Newby LK, Califf RM. Seeking the optimal aspirin dose in acute coronary syndromes. Am J Cardiol 2002; 90: 622-5.

[32] Antithrombotic Trialist's Collaboration. Collaborative metaanalysis of randomised trials of antiplatelet therapy for prevention of death, myocardial infarction, and stroke in high risk patients. $\mathrm{Br}$ Med J 2002; 324: 71-86.

[33] Harding SA, Din JN, Sarma J, et al. Flow cytometric analysis of circulating platelet-monocyte aggregates in whole blood: Methodological considerations. Thromb Haemost 2007; 98: 451-6.

[34] Inoue T, Hayashi M, Uchida T, Takayanagi K, Hayashi T, Morooka S. Significance of platelet aggregability immediately after blood sampling and effect of cigarette smoking. Platelets 2001; 12: 415-8.

[35] Roy S. Effects of smoking on prostacyclin formation and platelet aggregation in users of oral contraceptives. Am J Obstet Gynecol 1999; 180: S364-S8.

[36] Cha JK, Jeon HW, Kang MJ. ADP-induced platelet aggregation in acute ischemic stroke patients on aspirin therapy. Eur J Neurol 2008; 15: 1304-8.

[37] Barstad RM, Orvim U, Hamers MJ, Tjonnfjord GE, Brosstad FR, Sakariassen KS. Reduced effect of aspirin on thrombus formation at high shear and disturbed laminar blood flow. Thromb Haemost 1996; 75: 827-32.

[38] Levesque LE, Brophy JM, Zhang B. The risk for myocardial infarction with cyclooxygenase- 2 inhibitors: a population study of elderly adults. Ann Intern Med 2005; 142: 481-9.

[39] Moncada S, Vane JR. Interrelationships between prostacyclin and thromboxane A2. Ciba Found Symp 1980; 78: 165-83.

[40] FitzGerald GA, Brash AR, Falardeau P, Oates JA. Estimated rate of prostacyclin secretion into the circulation of normal man. J Clin Invest 1981; 68: 1272-6.

[41] Karniguian A, Legrand YJ, Caen JP. Prostaglandins: specific inhibition of platelet adhesion to collagen and relationship with cAMP level. Prostaglandins 1982; 23: 437-57.

[42] den Dekker E, Gorter G, Heemskerk JW, Akkerman JW. Development of platelet inhibition by cAMP during megakaryocytopoiesis. J Biol Chem 2002; 277: 29321-9.

[43] Fisch A, Tobusch K, Veit K, Meyer J, Darius H. Prostacyclin receptor desensitization is a reversible phenomenon in human platelets. Circulation 1997; 96: 756-60.

[44] Murata T, Ushikubi F, Matsuoka T, et al. Altered pain perception and inflammatory response in mice lacking prostacyclin receptor. Nature 1997; 388: 678-82.

[45] Arehart E, Stitham J, Asselbergs FW, et al. Acceleration of cardiovascular disease by a dysfunctional prostacyclin receptor mutation: potential implications for cyclooxygenase-2 inhibition. Circ Res 2008; 102: 986-93.

[46] Bolego C, Buccellati C, Radaelli T, et al. eNOS, COX-2, and prostacyclin production are impaired in endothelial cells from diabetics. Biochem Biophys Res Commun 2006; 339: 188-90.

[47] Barnard K. Viewpoint: an explanation for the cardiovascular effects of bevacizumab and rofecoxib? Circulation 2006; 114: f173f5.

[48] Aoyama T, Yui Y, Morishita H, Kawai C. Prostaglandin I2 half-life regulated by high density lipoprotein is decreased in acute myocardial infarction and unstable angina pectoris. Circulation 1990; 81: 1784-91

This is an open access article licensed under the terms of the Creative Commons Attribution Non-Commercial License (http://creativecommons.org/licenses/ by-nc/3.0/) which permits unrestricted, non-commercial use, distribution and reproduction in any medium, provided the work is properly cited. 